\title{
Article \\ Study on Fe-Based Metallic Glass Micro Hole Machining by Using Micro-EDM Combined with Electrophoretic Deposition Polishing
}

\author{
Hai-Ping Tsui * (D) and Shih-Yu Hsu
}

check for updates

Citation: Tsui, H.-P.; Hsu, S.-Y. Study on Fe-Based Metallic Glass Micro

Hole Machining by Using

Micro-EDM Combined with

Electrophoretic Deposition Polishing.

Processes 2022, 10,96. https://

doi.org/10.3390/pr10010096

Academic Editor: Jun Zhang

Received: 2 December 2021

Accepted: 31 December 2021

Published: 4 January 2022

Publisher's Note: MDPI stays neutral with regard to jurisdictional claims in published maps and institutional affiliations.

Copyright: (c) 2022 by the authors. Licensee MDPI, Basel, Switzerland. This article is an open access article distributed under the terms and conditions of the Creative Commons Attribution (CC BY) license (https:// creativecommons.org/licenses/by/ $4.0 /)$.

\author{
Department of Mechanical Engineering, National Central University, Taoyuan 32001, Taiwan; \\ yo3438389@gmail.com \\ * Correspondence: benno@ncu.edu.tw
}

\begin{abstract}
Fe-based metallic glass possesses high hardness and brittleness. It is a hard-to-cut metal material and difficult to machine by conventional methods. Although electrical discharge machining (EDM) has advantages in machining hard-to-cut metal materials, recast layer, pores, and micro cracks will form on the machined surface after machining. The study used a helical tool for the micro electrical discharge drilling ( $\mu$-EDD) process on Fe-based metallic glass. The influence of processing parameters, including the pulse on time, gap voltage, duty factor, and spindle rotational speed on the micro hole machining quality characteristics was investigated. The helical tool with SiC electrophoretic deposited (EPD) film was used to polish the inner surface of the electrical discharged micro hole. The findings show that the best micro hole accuracy, tool wear length, and inner surface were obtained at the spindle rotation speed of $1150 \mathrm{rpm}$, pulse on time of $5 \mu \mathrm{s}$, gap voltage of $30 \mathrm{~V}$, and duty factor of $40 \%$. The inner surface roughness can be reduced to $0.018 \mu \mathrm{m}$ by using EPD tool. The inner surface was polished up to form a mirror surface.
\end{abstract}

Keywords: micro-EDM; electrophoretic deposition polishing; metallic glass

\section{Introduction}

With the advancement of science and technology, the demand for high precision and micro parts has grown in many industries. The features of various parts and components have been developed towards precision and miniaturization, especially for micro shafts, micro holes, and micro-channels used in electronics, optical, medical, and biotechnology applications. The materials of the parts and components mentioned above, such as metallic glass, most often possess properties of high hardness and brittleness [1,2]. The use of conventional methods for machining metallic glass, especially in microfabrication, is difficult because of this hardness and brittleness.

Among the nontraditional machining methods used for precision and micro components, the most frequently used machining methods include electrical discharge machining (EDM) [3,4], ultrasonic machining [5], laser machining, electronic beam machining, ion beam machining [6], electrochemical machining, etching technique, and photoetching [7,8]. In the EDM process, the spark discharge generates high temperatures that melt and remove the material. The electrode tool does not touch the workpiece in the EDM process. Therefore, there is no cutting force during machining. EDM is extensively used for hard-to-cut metal materials. It is free from the influence of mechanical properties, such as the hardness, mechanical strength, and brittleness of materials. It can also achieve dimensional accuracy. There are several studies on micro-EDM drilling of micro holes [9-11], and vibration assisted micro-EDM drilling $[12,13]$. However, there is related research on micro hole drilling and polishing of hard-to-cut metal materials except iron-based metallic glass [14].

Although EDM has many advantages in machining hard-to-cut metal materials, there are problems of recast layer, pores, and micro cracks formed on the machined surface 
after machining [15-19]. The surface roughness is also worsened and the surface property is altered. Thus, the quality of machined surface is deteriorated after EDM. Therefore, subsequent processes may be required to improve EDM-machined surface quality. Additionally, the features of the precision and micro parts are very small, and general surface improving methods are not workable. Therefore, the current industries request a machining process to achieve micro holes and micro-channels with good surface quality and a low production cost for hard-to-cut materials. There are a number of studies on inner surface improvement [20-22]. However, there is no related research on the micro hole polishing of iron-based metallic glass.

Given that the traditional machining method is inapplicable for precision micro hole drilling of iron-based metallic glass, this study used a helical tool for the micro electrical discharge drilling ( $\mu$-EDD) process on Fe-based metallic glass and for polishing the inner surface of the micro hole by $\mathrm{SiC}$ electrophoretic deposited tool. The scanning electron microscope (SEM), the laser scanning confocal microscope (LSCM), and microscopic image measuring instrument were used to observe and measure the shape of the micro holes' inner walls and surface roughness, respectively. The experimental results reveal that the proposed method can overcome the drilling difficulties of iron-based metallic glass. The inner surface was also polished up to form a mirror surface. This paper presents an innovative hybrid method to obtain micro holes with good surface quality and low production cost. The achievements of this study can be applied to the manufacturing of micro molds, medical devices, and other products that are made of metallic glass.

\section{Materials and Methods}

\subsection{Experimental Equipment Layout}

The schematic diagram of the $\mu$-EDD experimental setup is shown in Figure 1. The EDM machine is Aristech CNC 250. The helical tungsten carbide electrode has a diameter of $300 \mu \mathrm{m}$. The helical electrode is clamped by a collet under the electrical discharge machine spindle and can be moved in the $\mathrm{Z}$ direction. The work-piece is a $1 \mathrm{~mm}$ thick iron-based metallic glass and fixed in the work tank. The DI water is supplied into the machining zone by a jet nozzle. A pulse current is applied to the helical electrode (cathode) and iron-based metallic glass work-piece (anode). The schematic diagram of the EPD experimental setup is shown in Figure 2. Figure 2a shows the schematic diagram of the helical tool coated with $\mathrm{SiC}$ particle film by the EPD phenomenon. The red brass cylindrical tank is used as the electrophoresis tank and the auxiliary electrode. The cylindrical tank is placed on the baffle board. The helical electrode is rotating while advancing into the electrophoresis tank. The power supply applies working voltage to the helical electrode (anode) and the auxiliary electrode (cathode). The voltage induces electrophoretic deposition reaction in the phenol formaldehyde resin solution. The helical tool is coated with $\mathrm{SiC}$ particles in the phenol formaldehyde resin solution as a polishing wheel by the EPD phenomenon. Figure $2 \mathrm{~b}$ shows the schematic diagram of the $\mathrm{SiC}$ particles film cured by the heating tube. The heating tube is placed on the baffle board. The helical electrode after the EPD process is moved into the heating tube in the $\mathrm{Z}$ direction. The electrophoretic deposited phenol formaldehyde resin with $\mathrm{SiC}$ particles film is cured by the heating tube. The polishing wheel is fabricated.

\subsection{Experimental Materials}

The iron-based metallic glass material made by casting is used as experimental workpiece, as shown in Figure 3a. The work-piece is $1 \mathrm{~mm}$ thick after grinding. The helical tungsten carbide electrode has a diameter of $300 \mu \mathrm{m}$, as also shown in Figure 3b. The composition of the iron-based metallic glass is shown in Table 1. 


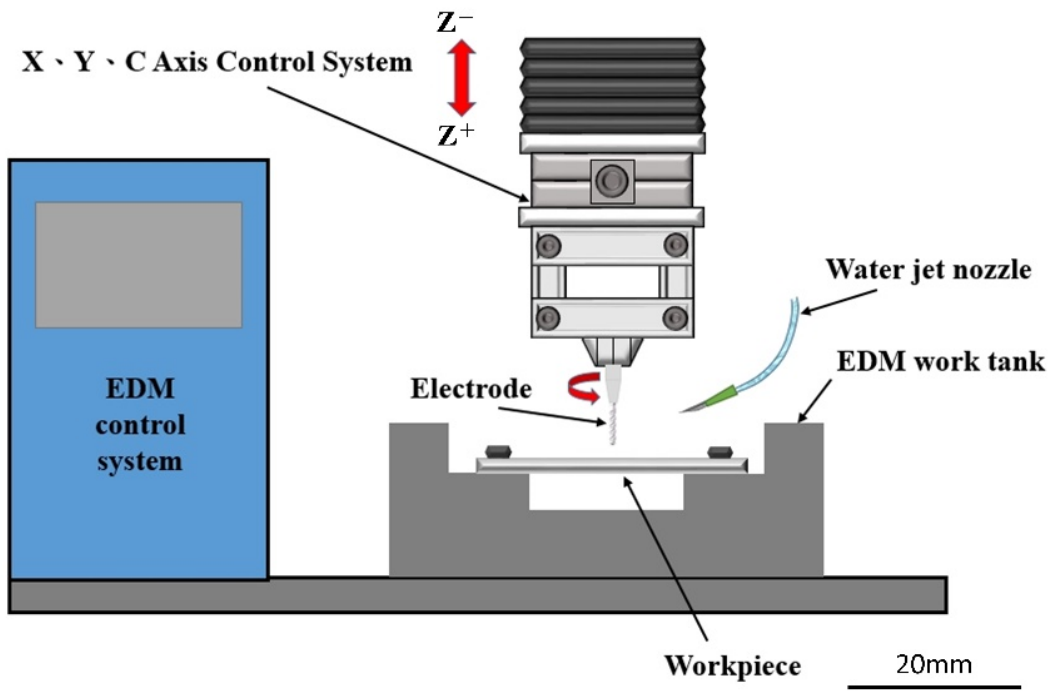

Figure 1. Schematic diagram of the $\mu$-EDD experimental setup.

(a)

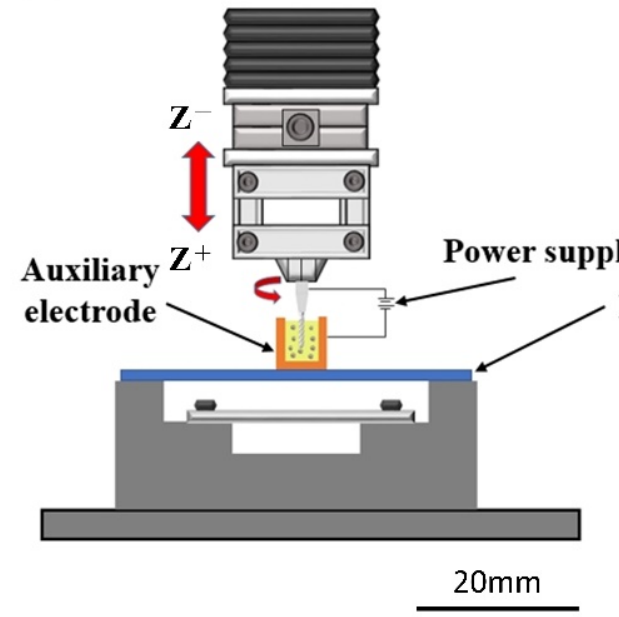

(b)

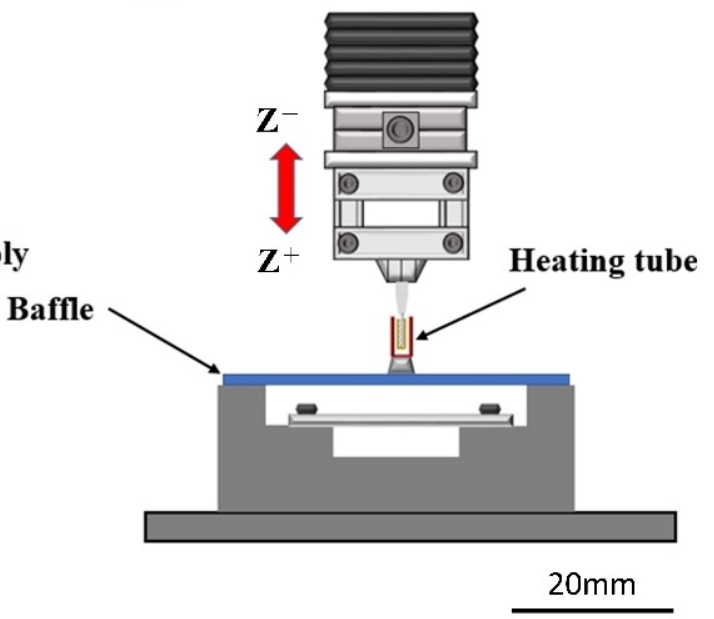

Figure 2. Schematic diagram of the EPD experimental setup. (a) Helical tool coated with $\mathrm{SiC}$ particle film by the EPD phenomenon. (b) SiC particles film cured by the heating tube.

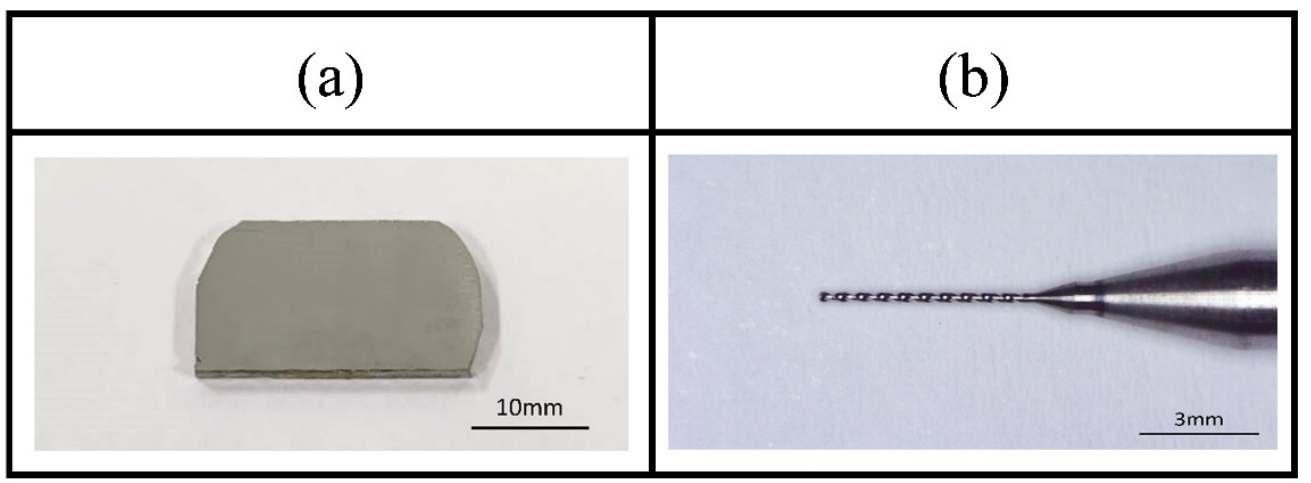

Figure 3. Photo of the (a) Fe-based metallic glass plate. (b) Helical tungsten carbide electrode. 
Table 1. Compositions of the iron-based metallic glass.

\begin{tabular}{cccccccc}
\hline & Fe & Cr & Mo & C & B & Y & Co \\
\hline Atom percent (\%) & 41 & 15 & 14 & 12 & 9 & 2 & 7 \\
Weight percent (\%) & 43.6 & 14.9 & 25.6 & 2.73 & 1.85 & 3.39 & 7.87 \\
\hline
\end{tabular}

\subsection{Experimental Procedures and Method}

The experimental process comprises three major parts. In the first part, the helical electrode is used for the $\mu$-EDD of iron-based metallic glass materials with different processing parameters, and the results are analyzed. In the second part, the helical tool is coated with $\mathrm{SiC}$ particles in a phenol formaldehyde resin solution as a polishing wheel with different processing parameters by the EPD phenomenon. In the third part, the tool being electrophoretic deposited of $\mathrm{SiC}$ particles is used to polish the inner surface of the electrical discharged micro hole. The microscopic image measuring instrument was $\mathrm{GH}$ 2010, which was used to observe the brightness of the micro holes' inner walls and measure the inlet and outlet diameter of the micro holes. The scanning electron microscope (SEM) was JEOL JSM 5610LV, which was used to observe the surface of the micro hole. The laser scanning confocal microscope (LSCM) was Keyence VK-X1000/1050, which was used to measure the surface roughness of the micro hole.

The constant parameters and setting values of the $\mu$-EDD experiment are shown in Table 2. The variable parameters and setting values of the $\mu$-EDD experiment are shown in Table 3. The influence of the processing parameters, including the pulse on time, gap voltage, duty factor, and spindle rotational speed on micro hole machining accuracy, machining time, and electrode wear length were investigated. The microscopic image measuring instrument and the SEM were used to measure the hole size and to observe the surface morphology, respectively.

Table 2. Constant parameters and setting values of the $\mu$-EDD experiments.

\begin{tabular}{cc}
\hline Parameters & Description \\
\hline Machining stroke $(\mathrm{mm})$ & 2 \\
Open voltage $(\mathrm{V})$ & 200 \\
Polarity & $(+)$ \\
Peak current $(\mathrm{mA})$ & 300 \\
Dielectric fluid & DI water \\
\hline
\end{tabular}

Table 3. Variable parameters and setting values of the $\mu$-EDD experiments.

\begin{tabular}{cc}
\hline Parameters & Value \\
\hline Pulse on time $(\mu \mathrm{s})$ & $5,10,15,20,25$ \\
Gap voltage $(\mathrm{V})$ & $30,35,40,45,50$ \\
Duty factor $(\%)$ & $20,30,40$ \\
Spindle rotational speed $(\mathrm{rpm})$ & $1150,1955,2760,3565,4370$ \\
\hline
\end{tabular}

The constant parameters and setting values of the EPD experiments are shown in Table 4. The variable parameters and setting values of the EPD experiments are shown in Table 5. The microscopic image measuring instrument is used to measure the outer diameter of the electrode and to observe the surface morphology, respectively. The constant parameters and setting values of the micro hole polishing experiment are shown in Table 6 . The microscopic image measuring instruments, SEM and LSCM were used to observe the surface morphology and to measure the surface roughness of the micro holes, respectively. 
Table 4. Constant parameters and setting values of the EPD experiments.

\begin{tabular}{cc}
\hline Parameters & Description \\
\hline SiC particle size $(\mu \mathrm{m})$ & $0.9 \sim 1.5$ \\
Phenol formaldehyde resin concentration $(\mathrm{wt} \%)$ & 20 \\
DI water $(\mathrm{wt} \%)$ & 57 \\
NaOH concentration $(\mathrm{wt} \%)$ & 3 \\
$\mathrm{SiC}$ particle concentration $(\mathrm{wt} \%)$ & 20 \\
Rotation speed $(\mathrm{rpm})$ & 100 \\
Curing temperature $\left({ }^{\circ} \mathrm{C}\right)$ & 130 \\
Curing time $(\mathrm{min})$ & 0.5 \\
\hline
\end{tabular}

Table 5. Variable parameters and setting values of the EPD experiments.

\begin{tabular}{cc}
\hline Parameters & Description \\
\hline Deposition time (s) & $0.5,1,1.5,2.0,2.5$ \\
Voltage (V) & $50,60,70,80,90$ \\
\hline
\end{tabular}

Table 6. Constant parameters and setting values of the micro hole polishing experiments.

\begin{tabular}{cc}
\hline Parameters & Description \\
\hline Rotation speed $(\mathrm{rpm})$ & 4020 \\
Machining feed $(\mu \mathrm{m} / \mathrm{s})$ & 5 \\
Initial gap $(\mu \mathrm{m})$ & 100 \\
Machining stroke $(\mathrm{mm})$ & 5 \\
DI water solution $(\mathrm{wt} \%)$ & 80 \\
$\mathrm{SiC}$ particle concentration $(\mathrm{wt} \%)$ & 20 \\
SiC particle size $(\mu \mathrm{m})$ & $0.9 \sim 1.5$ \\
\hline
\end{tabular}

\section{Experimental Results and Discussion}

\subsection{Experiments of Single Parameter of $\mu-E D D$}

The $\mu$-EDD was performed by using helical tool. The influence of processing parameters, including the pulse on time, gap voltage, duty factor, and spindle rotational speed on the micro hole machining accuracy, machining time, and electrode wear length, were investigated. The microscopic image measuring instrument is used to measure the electrode's outer diameter and to observe the surface morphology. The microscopic image measuring instrument and the SEM were used to measure the hole size and to observe the surface morphology, respectively.

\subsubsection{Influence of Pulse on Time on Micro Hole}

The relationship between pulse on time and inlet diameter is shown in Figure $4 \mathrm{a}$. When the pulse on time is $5 \mu \mathrm{s}$, the inlet diameter is $390 \mu \mathrm{m}$. The inlet diameter is $471 \mu \mathrm{m}$ when the pulse on time is $20 \mu \mathrm{s}$, and the inlet diameter is larger than that at $5 \mu$ s by $17 \%$. The discharge energy increased as the pulse on time increased. The phenomenon leads to large inlet diameter in the long pulse on time. The inlet diameter is decreased with the $25 \mu \mathrm{s}$ pulse on time, because the brittle material would break during long-term exposure to high temperatures, causing the material to rupture and peel off. The existence of chips increased the chance of developing the electrical discharge phenomenon. The number of discharges increased. The inlet diameter and machining time of the $\mu$-EDD are reduced. The inlet diameter is smaller and the surface morphology of the micro hole is better when the short pulse on time of $5 \mu \mathrm{s}$ is used. The relationship between pulse on time and outlet diameter is shown in Figure $4 \mathrm{~b}$. The trend of outlet diameter is relatively consistent with different pulse on time. The reason is that the electrode diameter decreases for high consumption under large discharge energy amounts. 
(a)

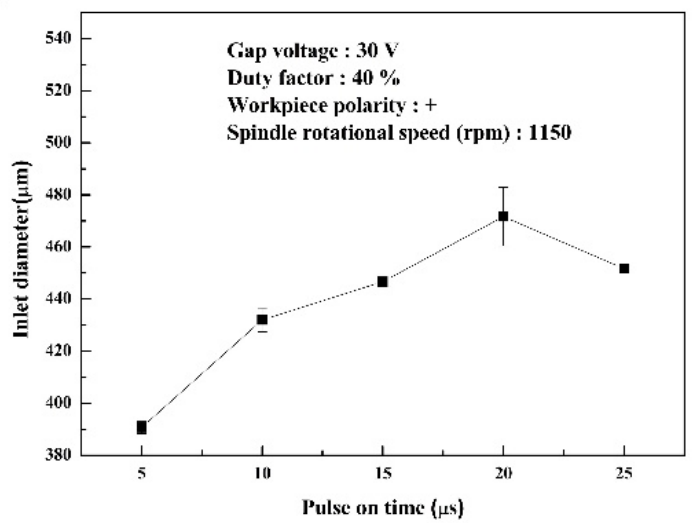

(c)

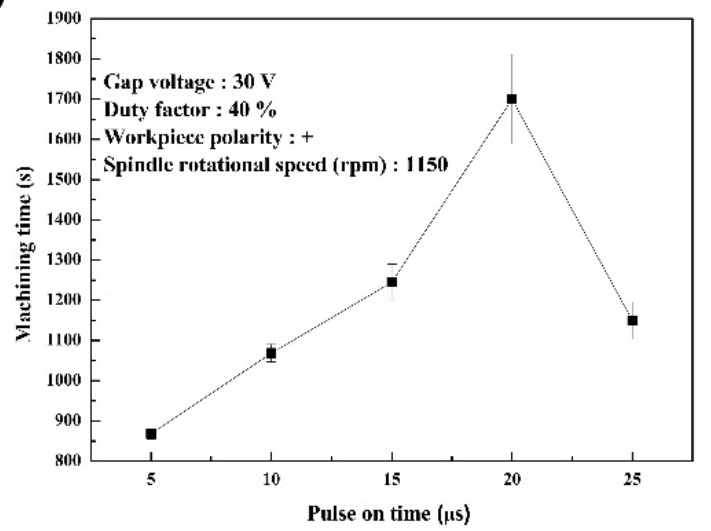

(b)

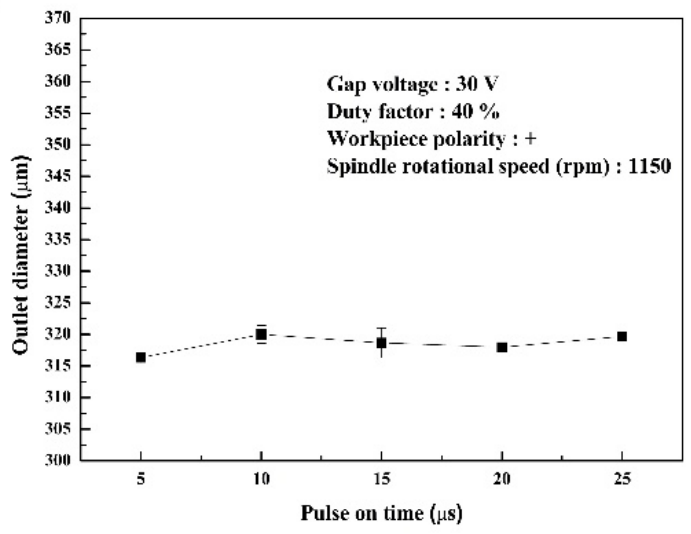

(d)

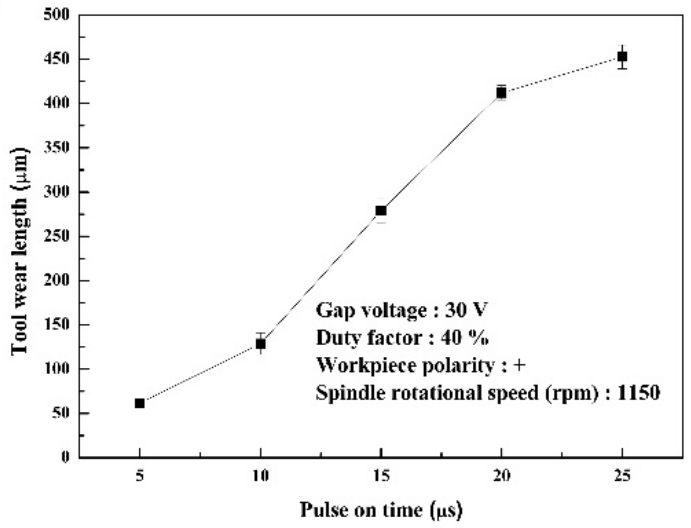

Figure 4. The relationship between pulse on time and (a) inlet diameter, (b) outlet diameter, and (c) machining time. (d) Length of electrode wear.

The relationship between pulse on time and machining time is shown in Figure 4c. When the pulse on time is $5 \mu \mathrm{s}$, the machining time is $868 \mathrm{~s}$. As the pulse on time increases from $5 \mu \mathrm{s}$ to $20 \mu \mathrm{s}$, the machining time increases to $1700 \mathrm{~s}$. The machining time of the pulse on time of $20 \mu$ s increases by $48 \%$ at compared with the pulse on time of $5 \mu$ s. In the case of $5 \mu$ s pulse on time, the discharge energy density is relatively appropriate and the machining time is the lowest. The discharge energy increases with the pulse on time. It is likely to induce concentrated discharging phenomenon in high pulse on time. The concentrated discharging phenomenon facilitates the long machining time at a high pulse on time. When the pulse on time is $25 \mu \mathrm{s}$, the machining time is shortened. This is because the spall chips easily cause the electrical discharge phenomenon and increase the number of discharges.

The relation between the pulse on time and the length of tool wear is shown in Figure $4 \mathrm{~d}$. The length of tool wear increases with the pulse on time. The discharge energy is increased with the pulse on time. The phenomenon facilitates a high length of tool wear in the long pulse on time.

Figure 5 shows the SEM image of the micro hole profile under different pulse on times. The SEM image shows that the overall discharged surface forms fine craters with the pulse on time of $5 \mu \mathrm{s}$. The surface morphology shows ruptured and spall craters with the pulse on time of $25 \mu \mathrm{s}$. Higher pulse on time will cause energy accumulation, which produce larger craters [23]. 


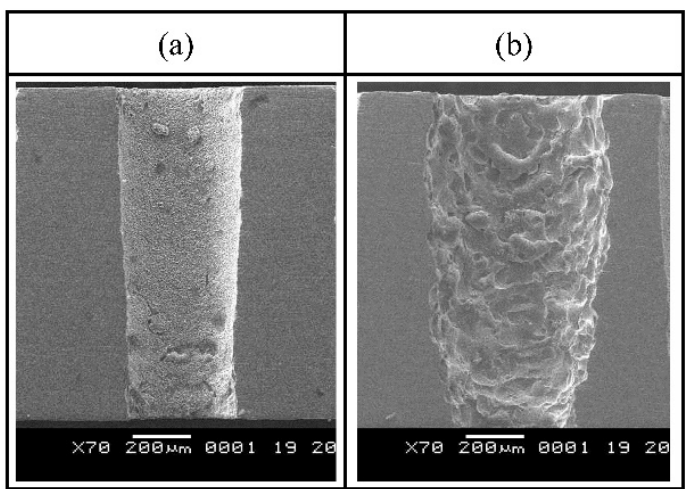

Figure 5. SEM image of micro hole profile under different pulse on time; (a) $5 \mu \mathrm{s}$, (b) $25 \mu \mathrm{s}$.

\subsubsection{Influence of Gap Voltage on Micro Hole}

The relation between the gap voltage and inlet diameter is shown in Figure 6a. When the gap voltage is $30 \mathrm{~V}$, the inlet diameter is $390 \mu \mathrm{m}$. As the gap voltage increases from $30 \mathrm{~V}$ to $50 \mathrm{~V}$, the inlet diameter is increased to $439 \mu \mathrm{m}$. The inlet diameter increases by $11 \%$ as compared to that under the condition of $30 \mathrm{~V}$. The inlet diameter increases with gap voltage. The higher the gap voltage is, the longer the discharging column will be. This is because more electrons escape from the cathode and impact the neutral particles in the dielectric fluid at the high gap voltage. The phenomenon generates greater ionization effect. The more the electrons impact the work-piece (anode), the larger the inlet diameter and outlet diameter will be.

(a)

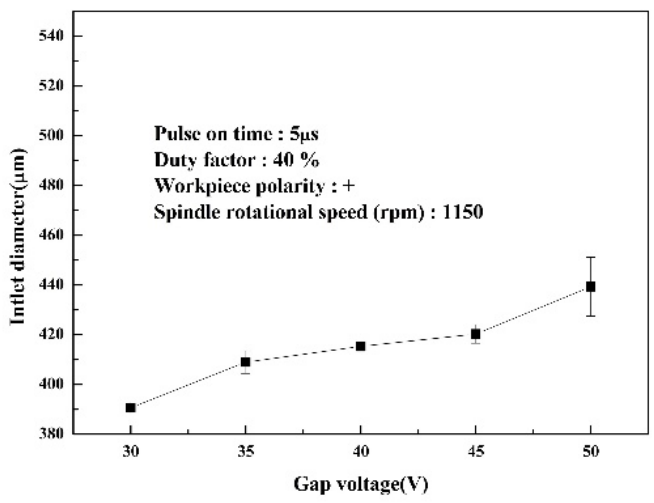

(c)

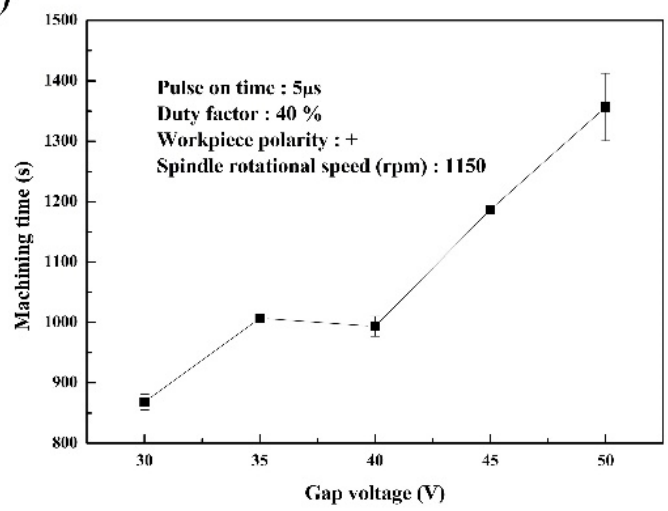

(b)

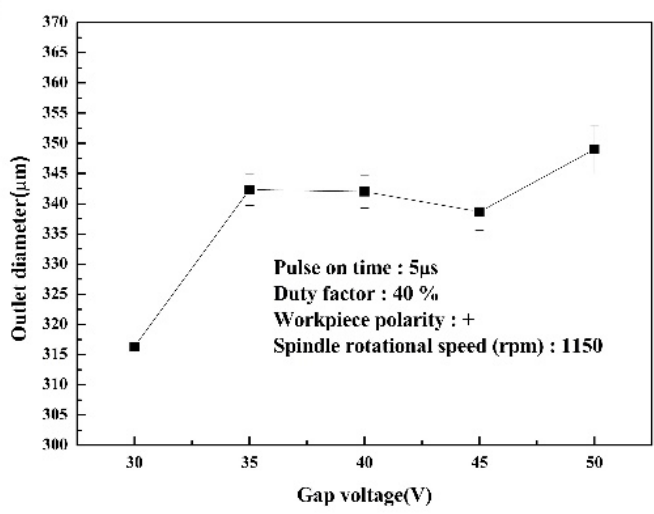

(d)

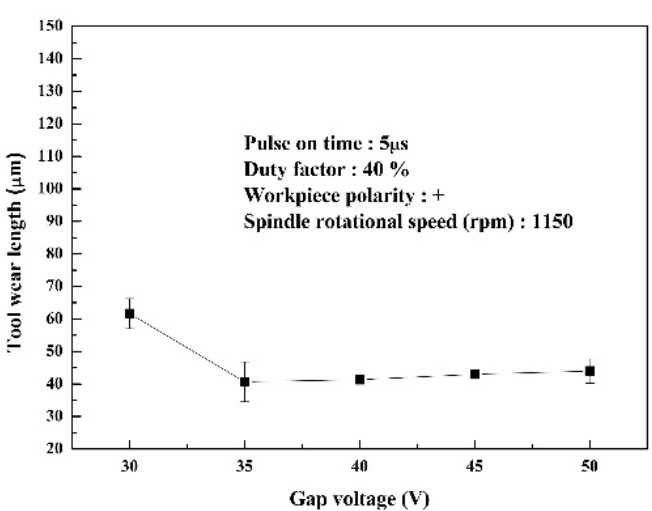

Figure 6. The relationship between gap voltage and (a) inlet diameter, (b) outlet diameter, and (c) machining time. (d) Length of electrode wear. 
The relation between the gap voltage and outlet diameter is shown in Figure 6b. When the gap voltage is $30 \mathrm{~V}$, the outlet diameter is $316 \mu \mathrm{m}$. As the gap voltage increases from $30 \mathrm{~V}$ to $50 \mathrm{~V}$, the outlet diameter increases to $349 \mu \mathrm{m}$. The outlet diameter is increased by $9 \%$ compared to that at a gap voltage of $30 \mathrm{~V}$.

The relation between the gap voltage and machining time is shown in Figure $6 \mathrm{c}$. When the gap voltage is $30 \mathrm{~V}$, the machining time is $868 \mathrm{~s}$. As the gap voltage is increased from $30 \mathrm{~V}$ to $50 \mathrm{~V}$, the machining time increases to $1356 \mathrm{~s}$. The machining time increases by $36 \%$ as compared to the gap voltage of $30 \mathrm{~V}$. The machining time increases with gap voltage. The relation between the gap voltage and the length of tool wear is shown in Figure 6d. When the gap voltage is $30 \mathrm{~V}$, the length of tool wear is $61 \mu \mathrm{m}$. The length of tool wear decreases as the gap voltage increases. When the gap voltage increases to $50 \mathrm{~V}$, the wear decreases to $44 \mu \mathrm{m}$ and the length of tool wear is reduced by $28 \%$ as compared to that at a gap voltage of $30 \mathrm{~V}$. The higher gap voltage enlarges the gap between the tool and work-piece. The large gap easily removes the debris, resulting in less tool wear.

Figure 7 shows the SEM image of the micro hole profile under different gap voltages. In the processing with a high gap voltage, the overall discharge surface forms fine discharge craters. The reason is that the high gap voltage results in a large gap between the tool and work-piece. There is adequate space for discharging the debris generated by the $\mu$-EDD process. The concentrated discharging phenomenon is less likely to form. The sidewall surface is unlikely to form ruptured and spalled craters due to high heat accumulation [24].

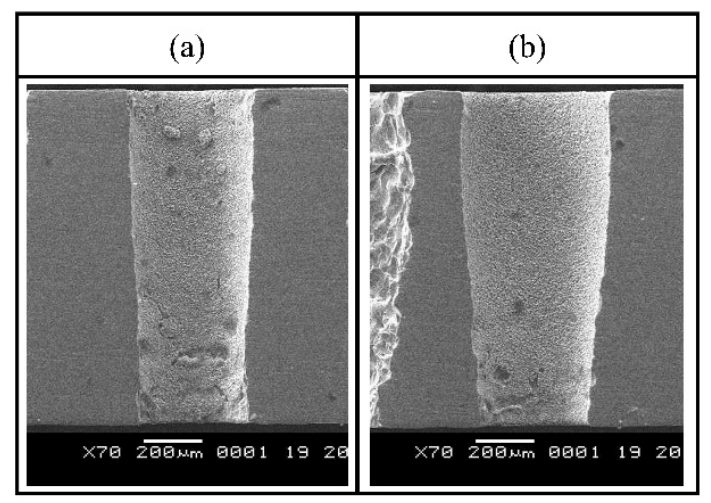

Figure 7. SEM image of micro hole profile under different gap voltage; (a) $30 \mathrm{~V}$, (b) $50 \mathrm{~V}$.

\subsubsection{Influence of Duty Factor on Micro Hole}

The relation between the duty factor and inlet diameter is shown in Figure 8a. When the duty factor is $20 \%$, the inlet diameter is $434 \mu \mathrm{m}$. As the duty factor increases from $20 \%$ to $40 \%$, the inlet diameter is decreased to $390 \mu \mathrm{m}$. The inlet diameter reduces by $10 \%$ as compared to the condition of $20 \%$. The inlet diameter decreases as the duty factor increases. In the processing with the low duty factor, the material removal rate is low. The machining time shortens as the duty factor increases. The total discharging time of the low duty factor on the lateral side of the micro hole is longer than the total discharging time of the high duty factor. Therefore, the inlet diameter is increased during the processing with a low duty factor. The relation between the duty factor and outlet diameter is shown in Figure $8 \mathrm{~b}$. The outlet diameter is increased when the duty factor is $20 \%$, and the reason is the same as the inlet diameter.

The relation between duty factor and machining time is shown in Figure 8c. When the duty factor is $20 \%$, the required machining time is $3324 \mathrm{~s}$. As the duty factor increases from $20 \%$ to $40 \%$, the machining time is shortened to $868 \mathrm{~s}$. The machining time reduces by $74 \%$ as compared to the duty factor of $20 \%$. The machining time becomes longer as the duty factor decreases. The pulse on time is only $20 \%$ of the pulse period, meaning the pulse off time is much longer than the pulse on time. Therefore, the material removal rate is decreased due to the low discharge energy. The relation between the duty factor and the tool wear length is shown in Figure $8 \mathrm{~d}$. Among the duty factor parameters, there is no 
significant change in the length of electrode wear. Figure 9 shows the SEM image of the micro hole profile under different duty factors. The overall discharged surface of a duty factor of $20 \%$ is worse than at a duty factor of $40 \%$. The low duty factor results in increased lateral discharges and a longer machining time. The work piece material is likely to form ruptured and spall craters due to high heat accumulation at a duty factor of $20 \%$, thus the surface morphology is worse.

(a)

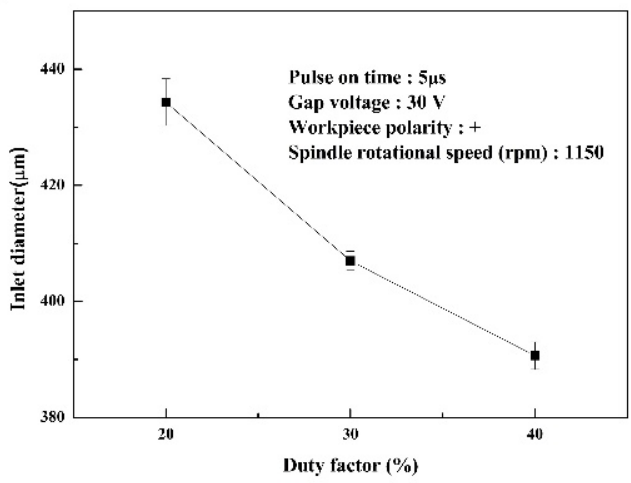

(c)

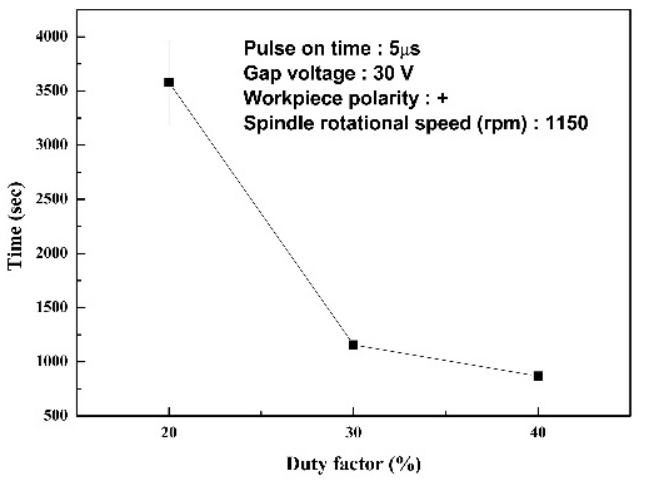

(b)

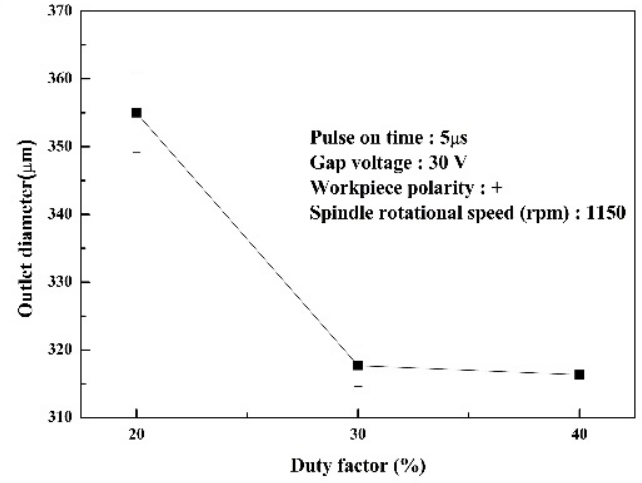

(d)

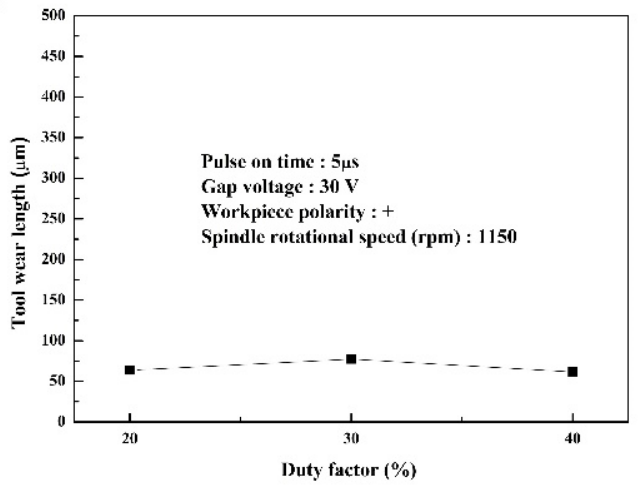

Figure 8. The relationship between duty factor and (a) inlet diameter, (b) outlet diameter, and (c) machining time. (d) Length of electrode wear.

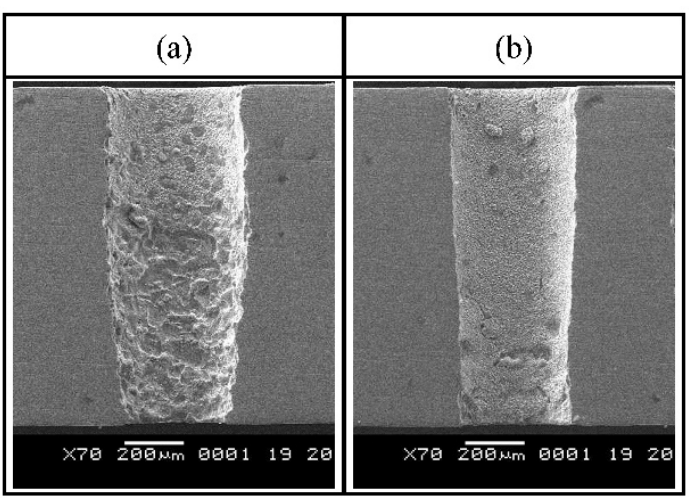

Figure 9. SEM image of micro hole profile under different duty factor; (a) 20\%, (b) $40 \%$.

\subsubsection{Influence of Spindle Rotation Speed on Micro Hole}

The relation between the spindle rotation speed and inlet diameter is shown in Figure 10a. When the spindle rotation speed is $1150 \mathrm{rpm}$, the inlet diameter is $390 \mu \mathrm{m}$. As the electrode rotation speed is increased from $1150 \mathrm{rpm}$ to $4370 \mathrm{rpm}$, the inlet diameter is increased to $429 \mu \mathrm{m}$. The inlet diameter increases by $9 \%$ as compared with that under the condition of $1150 \mathrm{rpm}$. As this experiment uses helical electrode as the experimental 
electrode, the area of the electrode side edge and tip sweeping the surface of the micro hole increases as the spindle rotation speed increases. Therefore, higher electrode rotation speed generates more discharges and discharge energy. The larger discharge energy increases the inlet diameter. However, the inlet diameter becomes stable when the spindle rotation speed is over $1955 \mathrm{rpm}$, because the hole gap is too large to discharge the sidewall of the micro hole. The relation between the spindle rotation speed and outlet diameter is shown in Figure 10b. When the electrode rotation speed is $1150 \mathrm{rpm}$, the outlet diameter is $316 \mu \mathrm{m}$. As the electrode rotation speed increases from $1150 \mathrm{rpm}$ to $4370 \mathrm{rpm}$, the outlet diameter increases to $351 \mu \mathrm{m}$, because higher spindle rotation speed can make the machining fluid circulate better. The outlet diameter is increased by $11 \%$ compared with that under the condition of $1150 \mathrm{rpm}$.

(a)

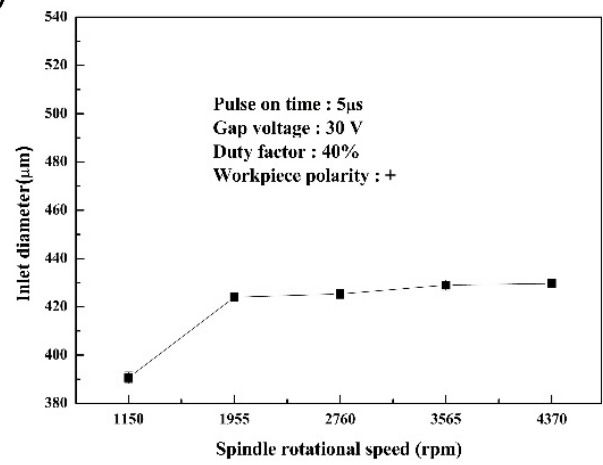

(c)

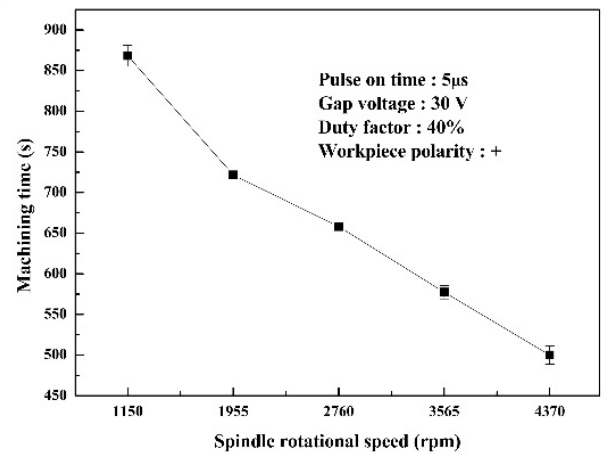

(b)

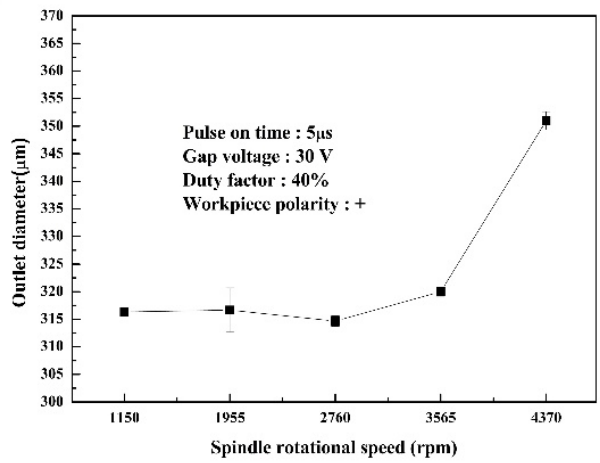

(d)

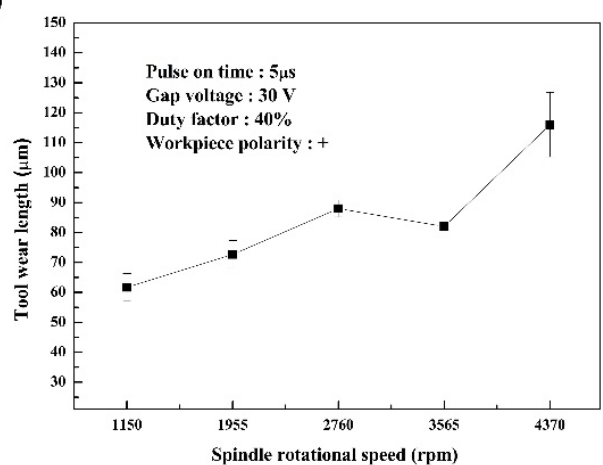

Figure 10. The relationship between spindle rotational speed and (a) inlet diameter, (b) outlet diameter, and (c) machining time. (d) Length of electrode wear.

The relation between the spindle rotation speed and machining time is shown in Figure 10c. When the spindle rotation speed is $1150 \mathrm{rpm}$, the machining time is $868 \mathrm{~s}$. As the spindle rotation speed is increased from $1150 \mathrm{rpm}$ to $4370 \mathrm{rpm}$, the machining time is shortened to $500 \mathrm{~s}$. The machining time reduces by $42 \%$ as compared with that under the condition of $1150 \mathrm{rpm}$. The relation between the spindle rotation speed and the length of tool wear is shown in Figure 10d. When the spindle rotation speed is $1150 \mathrm{rpm}$, the length of tool wear is $61 \mu \mathrm{m}$. When the spindle rotation speed is increased to $4370 \mathrm{rpm}$, the length of tool wear is increased to $116 \mu \mathrm{m}$. The length of tool wear increases by $47 \%$ as compared with that under the condition of $1150 \mathrm{rpm}$. The reason is that higher spindle rotation speed generates more discharges and discharge energy, resulting in increasing trend. When the discharge energy is increased, the machining time is decreased and the length of tool wear is increased.

Figure 11 shows the SEM image of the micro hole profile under different spindle rotation speed. As more discharges are generated at higher spindle rotation speeds, the overall discharged surface has severe molten accumulation and ruptured craters. The 
overall discharged surface at a spindle rotation speed of $4370 \mathrm{rpm}$ is worse than that at a spindle rotation speed of $1150 \mathrm{rpm}$.

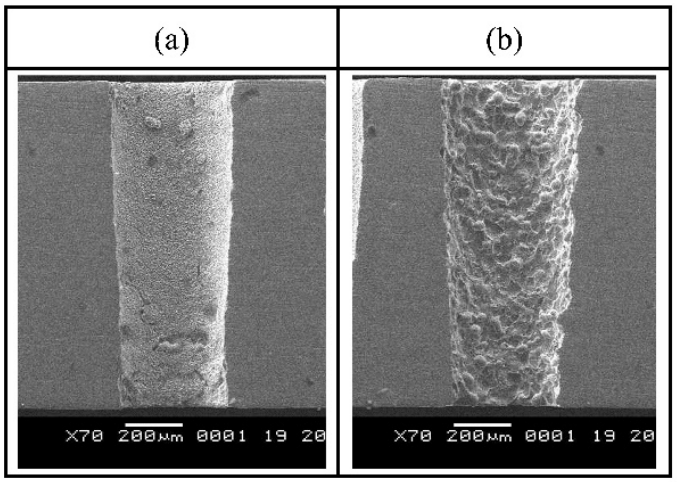

Figure 11. SEM image of the micro hole profile under different spindle rotation speed; (a) $1150 \mathrm{rpm}$ (b) $4370 \mathrm{rpm}$.

\subsection{Experiments of Parameters of Electrophoretic Deposition Polishing}

The helical tool is coated with $\mathrm{SiC}$ particles in a phenol formaldehyde resin solution and used as a polishing wheel by the EPD phenomenon after the $\mu$-EDD experiments. The influence of the electrophoresis parameters, including the deposition time and coating voltage, on the diameter of the deposited tool after electrophoretic deposition are discussed. The feature and diameter of the EPD are observed and measured by using a microscopic image measuring instrument. The EPD polishing wheel was used to polish the inner surface of the electrical discharged micro hole. The SEM and the LSCM were used to observe and measure the shape of the micro holes' inner walls and the surface roughness, respectively.

\subsubsection{Influence of Deposition Time and Coating Voltage on EPD Polishing Wheel}

Figure 12a shows the relation between the deposition time and deposition diameter. When the deposition time increases to $1.5 \mathrm{~min}$, the deposition diameter reaches the limit. The reason is that the helical tool (anode) is wrapped in SiC film. The SiC film formed an insulating barrier between the cathode and anode. Therefore, although the deposition time increases, the $\mathrm{SiC}$ powder deposition thickness on the helical tool does not continue to increase. The deposition diameter is $450 \mu \mathrm{m}$ when the deposition time is $1.5 \mathrm{~min}$; there is adequate diameter contact for the micro hole, thus the selected deposition time is $1.5 \mathrm{~min}$.

(a)

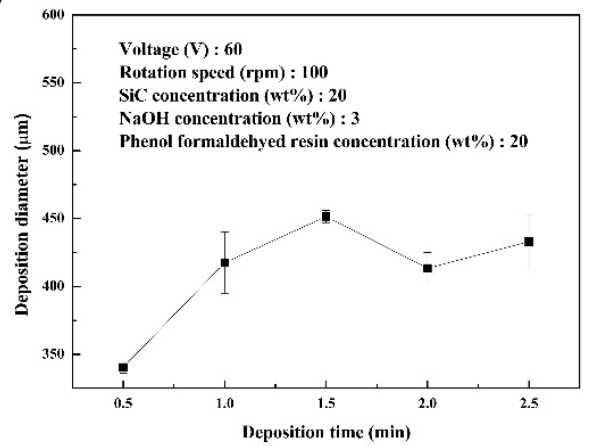

(b)

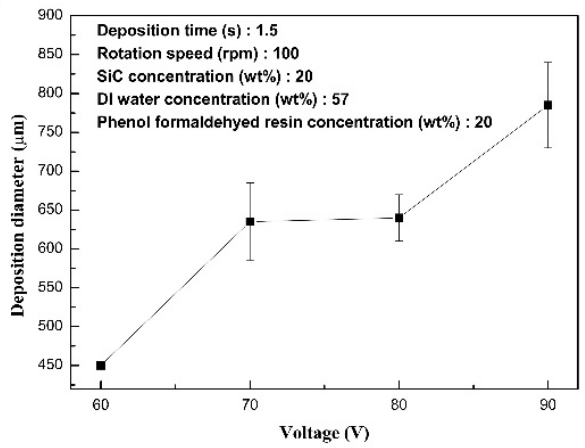

Figure 12. The relation between (a) the deposition time and deposition diameter. (b) The voltage and deposition diameter.

According to Figure 12b, the coating voltage is positively correlated with the SiC powder deposition thickness. The higher the coating voltage is, the larger the deposition diameter is. It is found in the previous experiments that the EPD polishing wheel with a larger deposition diameter became broken during the polishing process. Therefore, the 
selected coating voltage is $60 \mathrm{~V}$. This is because the diameter of the micro hole is $390 \mu \mathrm{m}$ after the $\mu$-EDD process, and the deposition diameter of the polishing wheel is $450 \mu \mathrm{m}$. The EPD polishing wheel diameter has appropriate contact with the micro hole.

\subsubsection{Discussion of the Polishing Results}

The EPD polishing wheel was used to polish the inner surface of the electrical discharged micro hole. The constant parameters and setting values of the micro hole polishing experiment are shown in Table 6. The surface roughness of the inner surface of the micro hole is measured at three positions, which are the top position, the middle position, and the bottom position. Figure 13 shows the relation between the measuring position and surface roughness. The surface roughness at the top position, the middle position and the bottom position are $0.519 \mu \mathrm{m}, 0.427 \mu \mathrm{m}$ and $0.628 \mu \mathrm{m}$, respectively, after the $\mu$-EDD process. The surface roughness at the top position, the middle position, and the bottom position are $0.035 \mu \mathrm{m}, 0.018 \mu \mathrm{m}$ and $0.050 \mu \mathrm{m}$ after the polishing experiment, respectively, which are lower than those of before polishing by $93 \%, 96 \%$ and $92 \%$, respectively. The improvement is significant. Figure 14 shows the photo and SEM images of the micro hole before and after polishing. The pores formed on the $\mu$-EDD surface have been removed after polishing. The inner surface of the micro hole after polishing reached a mirror surface grade.

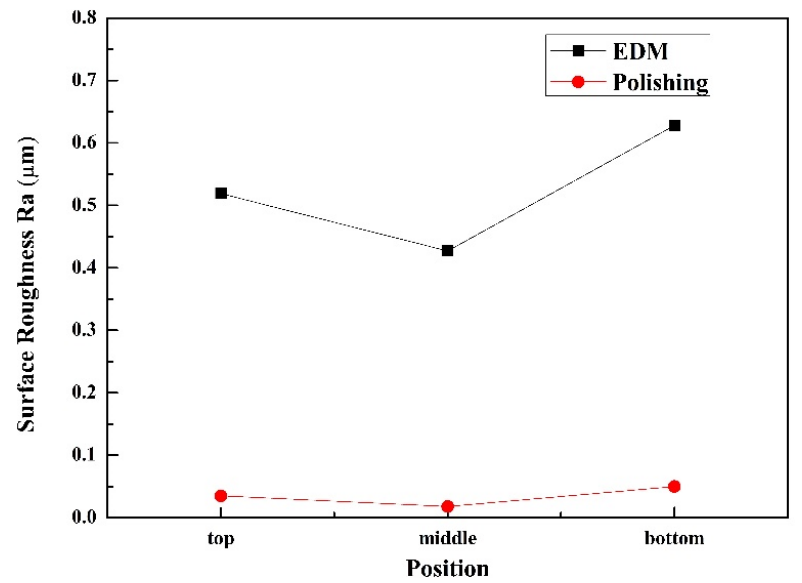

Figure 13. Shows the relation between the measuring position and surface roughness.

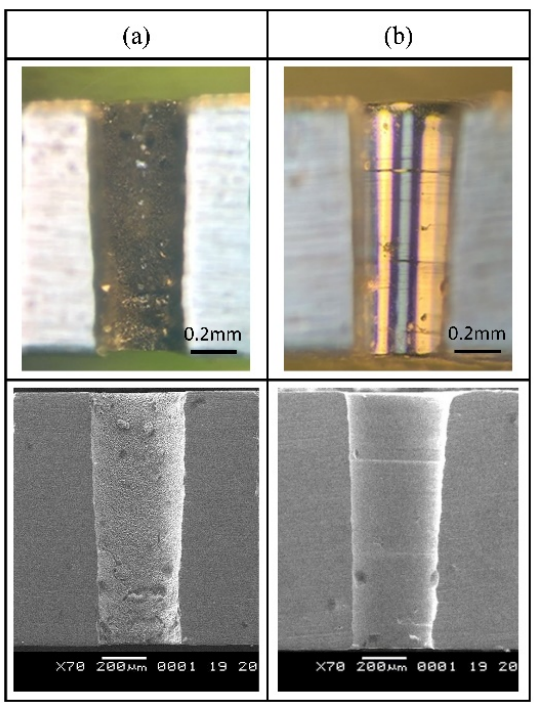

Figure 14. Photo and SEM images of the micro hole before and after polishing. (a) Before polishing. (b) After polishing. 


\section{Conclusions}

This study used a helical tool for the $\mu$-EDD process on Fe-based metallic glass and for polishing the inner surface of the micro hole by SiC electrophoretic deposited tool. Micro holes with good surface quality can be obtained by using the hybrid method mentioned above. The results reveal that the hybrid method can overcome the drilling difficulties of iron-based metallic glass. The following conclusions are drawn.

1. The discharge energy increases with the pulse on time. The phenomenon facilitates a large inlet diameter during a long pulse on time. When the pulse on time increases from $5 \mu$ s to $20 \mu \mathrm{s}$, the machining time is increased by $48 \%$. When the pulse on time increases from $5 \mu$ s to $25 \mu$ s, the length of electrode wear is increased by $86 \%$. When the pulse on time is long, the brittle material breaks during long-term exposure to high temperatures, and the material of the inner surface of the micro hole is ruptured and peeled off. The surface morphology shows ruptured and spall craters at the pulse on time of $25 \mu \mathrm{s}$.

2. The higher the gap voltage is, the longer the discharging column will be. The long discharging column results in a high discharge energy. When the gap voltage increases from $30 \mathrm{~V}$ to $50 \mathrm{~V}$, the inlet diameter, the outlet diameter, and processing time are increased by $11 \%, 9 \%$, and $36 \%$, respectively. The length of tool wear decreases as the gap voltage increases. The higher gap voltage enlarges the gap between the tool and work-piece. The large gap easily removes the debris, resulting in less tool wear.

3. The machining time shortens as the duty factor increases. The low duty factor results in more lateral discharges and longer machining time. The work piece material is likely to form rupture and spall craters due to high heat accumulation at the duty factor of $20 \%$. Therefore, the surface morphology is worse. Among the duty factor parameters, there is no significant change in the length of electrode wear.

4. The area of the helical electrode's side edge and tip sweeping the surface of the micro hole increases with the spindle rotation speed. Therefore, the higher helical electrode rotation speed generates more discharges and greater discharge energy. The inlet diameter, the outlet diameter, and the length of tool wear increases with the spindle rotation speed.

5. The best micro hole accuracy, tool wear length, and inner surface were obtained at the spindle rotation speed of $1150 \mathrm{rpm}$, pulse on time of $5 \mu \mathrm{s}$, gap voltage of $30 \mathrm{~V}$, and duty factor of $40 \%$. The surface roughness of the work-piece can be reduced from $0.427 \mu \mathrm{m}$ to $0.018 \mu \mathrm{m}$ after the inner surface polishing by using $\mathrm{SiC}$ electrophoretic deposited tool. The inner surface was polished up to form a mirror surface.

Author Contributions: Conceptualization, H.-P.T. and S.-Y.H.; Methodology, H.-P.T. and S.-Y.H.; Data curation, S.-Y.H.; Visualization, H.-P.T. and S.-Y.H.; Investigation, H.-P.T. and S.-Y.H.; Supervision, H.-P.T.; Writing—review and editing, H.-P.T.; Writing—original draft preparation, H.-P.T. All authors have read and agreed to the published version of the manuscript.

Funding: The authors would like to thank the Ministry Science and Technology of the Republic of China, Taiwan, for financially supporting this research under Contract No. MOST 107-2218E-008-010-MY2.

Institutional Review Board Statement: Not applicable.

Informed Consent Statement: Informed consent was obtained from all subjects involved in the study.

Data Availability Statement: The data and materials are available.

Conflicts of Interest: The authors declare no conflict of interest. 


\section{References}

1. Koshiba, H.; Inoue, A.; Makino, A. Fe-Based Soft Magnetic Amorphous Alloys with a Wide Supercooled Liquid Region. J. Appl. Phys. 1999, 85, 5136-5138. [CrossRef]

2. Hua, D.; Xia, Q.; Wang, W.; Zhou, Q.; Li, S.; Qian, D.; Shi, J.; Wang, H. Atomistic Insights into the Deformation Mechanism of a CoCrNi Medium Entropy Alloy under Nanoindentation. Int. J. Plast. 2021, 142, 102997. [CrossRef]

3. Kagaya, K.; Ōishi, Y.; Yada, K. Micro-Electrodischarge Machining Using Water as a Working Fluid-I: Micro-Hole Drilling. Precis. Eng. 1986, 8, 157-162. [CrossRef]

4. Kumar, K.; Kumar Rawal, S.; Singh, V.P.; Bala, A. Experimental Study on Diametric Expansion and Taper Rate in EDM Drilling For High Aspect Ratio Micro Holes in High Strength Materials. Mater. Today: Proc. 2018, 5, 7363-7372. [CrossRef]

5. Sun, X.-Q.; Masuzawa, T.; Fujino, M. Micro Ultrasonic Machining and Its Applications in MEMS. Sens. Actuators A Phys. 1996, 57, 159-164. [CrossRef]

6. Choi, S.S.; Jung, M.Y.; Kim, D.W.; Yakshin, M.A.; Park, J.Y.; Kuk, Y. Fabrication of Microelectron Gun Arrays Using Laser Micromachining. Microelectron. Eng. 1998, 41-42, 167-170. [CrossRef]

7. Ehrfeld, W.; Lehr, H. Deep X-Ray Lithography for the Production of Three-Dimensional Microstructures from Metals, Polymers and Ceramics. Radiat. Phys. Chem. 1995, 45, 349-365. [CrossRef]

8. Kupka, R.K.; Bouamrane, F.; Cremers, C.; Megtert, S. Microfabrication: LIGA-X and Applications. Appl. Surf. Sci. 2000, 164, 97-110. [CrossRef]

9. Nirala, C.K.; Saha, P. Precise MEDM-Drilling Using Real-Time Indirect Tool Wear Compensation. J. Mater. Processing Technol. 2017, 240, 176-189. [CrossRef]

10. Huang, T.-W.; Sheu, D.-Y. High Aspect Ratio of Micro Hole Drilling by Micro-EDM with Different Cross-Section Shape Micro Tools for Flushing Process. Procedia CIRP 2020, 95, 550-553. [CrossRef]

11. Maccarini, G.; Pellegrini, G.; Ravasio, C. Effects of the Properties of Workpiece, Electrode and Dielectric Fluid in Micro-EDM Drilling Process. Procedia Manuf. 2020, 51, 834-841. [CrossRef]

12. Unune, D.R.; Nirala, C.K.; Mali, H.S. Accuracy and Quality of Micro-Holes in Vibration Assisted Micro-Electro-Discharge Drilling of Inconel 718. Measurement 2019, 135, 424-437. [CrossRef]

13. Jahan, M.P.; Wong, Y.S.; Rahman, M. Evaluation of the Effectiveness of Low Frequency Workpiece Vibration in Deep-Hole Micro-EDM Drilling of Tungsten Carbide. J. Manuf. Processes 2012, 14, 343-359. [CrossRef]

14. Liu, H.S.; Yan, B.H.; Chen, C.L.; Huang, F.Y. Application of Micro-EDM Combined with High-Frequency Dither Grinding to Micro-Hole Machining. Int. J. Mach. Tools Manuf. 2006, 46, 80-87. [CrossRef]

15. Lee, S.H.; Li, X. Study of the Surface Integrity of the Machined Workpiece in the EDM of Tungsten Carbide. J. Mater. Processing Technol. 2003, 139, 315-321. [CrossRef]

16. Lee, H.T.; Tai, T.Y. Relationship between EDM Parameters and Surface Crack Formation. J. Mater. Processing Technol. 2003, 142, 676-683. [CrossRef]

17. Simao, J.; Lee, H.G.; Aspinwall, D.K.; Dewes, R.C.; Aspinwall, E.M. Workpiece Surface Modification Using Electrical Discharge Machining. Int. J. Mach. Tools Manuf. 2003, 43, 121-128. [CrossRef]

18. Li, G.; Natsu, W.; Yu, Z. Study on Quantitative Estimation of Bubble Behavior in Micro Hole Drilling with EDM. Int. J. Mach. Tools Manuf. 2019, 146, 103437. [CrossRef]

19. Wu, Y.-Y.; Huang, T.-W.; Sheu, D.-Y. Desktop Micro-EDM System for High-Aspect Ratio Micro-Hole Drilling in Tungsten Cemented Carbide by Cut-Side Micro-Tool. Micromachines 2020, 11, 675. [CrossRef] [PubMed]

20. Tsui, H.-P.; Hung, J.-C.; Wu, K.-L.; You, J.-C.; Yan, B.-H. Fabrication of a Microtool in Electrophoretic Deposition for Electrochemical Microdrilling and in Situ Micropolishing. Mater. Manuf. Processes 2011, 26, 740-745. [CrossRef]

21. Dong, S.; Wang, Z.; Wang, Y.; Zhang, J. Micro-EDM Drilling of High Aspect Ratio Micro-Holes and in Situ Surface Improvement in C17200 Beryllium Copper Alloy. J. Alloy. Compd. 2017, 727, 1157-1164. [CrossRef]

22. Cheng, K.-C.; Chen, K.-Y.; Tsui, H.-P.; Wang, A.-C. Characteristics of the Polishing Effects for the Stainless Tubes in Magnetic Finishing with Gel Abrasive. Processes 2021, 9, 1561. [CrossRef]

23. Zhang, M.; Zhang, Q.; Dou, L.; Liu, Q.; Dong, C. Comparisons of Single Pulse Discharge Crater Geometries in EDM and EAM. J. Manuf. Processes 2016, 22, 74-81. [CrossRef]

24. Nguyen, P.H.; Banh, T.L.; Mashood, K.A.; Tran, D.Q.; Dong Pham, V.; Muthuramalingam, T.; Duc Nguyen, V.; Nguyen, D.T. Application of TGRA-Based Optimisation for Machinability of High-Chromium Tool Steel in the EDM Process. Arab. J. Sci. Eng. 2020, 45, 5555-5562. [CrossRef] 